\title{
Levantamento florístico na Caatinga: comparação entre uma área preservada e uma área degradada no Sertão Pernambucano
}

Floristic survey in the Caatinga: comparison between a preserved area and a degraded area in the Sertão Pernambucano

Encuesta florística en la Caatinga: comparación entre un área preservada y un área degradada en el Sertão Pernambucano

Recebido: 02/09/2021 | Revisado: 10/09/2021 | Aceito: 12/09/2021 | Publicado: 13/09/2021

\author{
Maria Janaina Lira Vital \\ ORCID: https://orcid.org/0000-0001-7396-0940 \\ Faculdade de Ciências Humanas do Sertão Central, Brasil \\ E-mail: maria.vital@prof.ce.gov.br \\ Gilian Clebson Pereira Alves \\ ORCID: https://orcid.org/0000-0003-0563-7863 \\ Faculdade de Ciências Humanas do Sertão Central, Brasil \\ E-mail: gilianclebson2017@gmail.com \\ Arlene Alves da Silva \\ ORCID: https://orcid.org/0000-0002-8945-2606 \\ Faculdade de Ciências Humanas do Sertão Central, Brasil \\ E-mail: arlenesilvaa@hotmail.com \\ Maria do Socorro Germano de Oliveira \\ ORCID: https://orcid.org/0000-0003-3814-1733 \\ Faculdade de Ciências Humanas do Sertão Central, Brasil \\ E-mail: socorrogermano2017@gmail.com
}

\begin{abstract}
Resumo
O objetivo desse trabalho foi coletar e identificar espécies nativas da composição florista em duas áreas diferentes na cidade de Salgueiro-PE. A coleta foi realizada no município Formiga, em uma área de mata nativa preservada e no sítio Uri, onde foi visto a área degradada. Em todas as áreas foram demarcados 2 transectos retangulares (10x30m) distribuídos no entorno de cada área, cada transecto era composto por três parcelas quadrangulares (10x20m) separadas por um intervalo de $10 \mathrm{~m}$. Foram coletadas 102 espécies na área degradada e distribuídas em famílias botânicas. Na área preservada foram encontrados 375 indivíduos pertencentes a famílias e espécies diferentes, possuindo um número maior de espécies, ou seja, uma maior biodiversidade e uma rica variedade arbóreo-arbustiva em relação a área degradada. O valor encontrado de Shannon-Weaver (H') na área degradada (A) 1, 75 e na área preservada (B) 2,51, indicando que área B é mais diversa e que A. E quanto ao índice de dominância de Simpson (C) o valor observado foi de 0,90 na área (A) e 0,76 na área (B). Os valores observados de equabilidade foi de foi de 0,90 para a área preservada e 0,84 para a área degradada, ou seja, o baixo valor reflete que há uma menor uniformidade referente à distribuição vegetal na área degradada. De cordo com os índices de diversidade podemos perceber que a área degradada perde sua diversidade em espécies, ou seja, perde sua riqueza que pode influenciar nas características do solo, da fauna e nas interações bióticas e abióticas.
\end{abstract}

Palavras-chave: Caatinga; Espécies; Índices; Preservação.

\begin{abstract}
The objective of this work was to collect and identify native species of the florist composition in two different areas in the city of Salgueiro-PE. The collection was carried out in the municipality of Formiga, in an area of preserved native forest and in the Uri site, where the degraded area was seen. In all areas, 2 rectangular transects $(10 \times 30 \mathrm{~m})$ were demarcated and distributed around each area, each transect was composed of three quadrangular plots (10x20m) separated by an interval of $10 \mathrm{~m} .102$ species were collected in the degraded area and distributed in botanical families. In the preserved area, 375 individuals belonging to different families and species were found, having a greater number of species, that is, greater biodiversity and a rich variety of trees and shrubs in relation to the degraded area. The Shannon-Weaver $\left(\mathrm{H}^{\prime}\right)$ value found in the degraded area (A) 1.75 and in the preserved area (B) 2.51, indicating that area B is more diverse and that A. What about Simpson's dominance index (C) the observed value was 0.90 in area (A) and 0.76 in area (B). The observed values of evenness were 0.90 for the preserved area and 0.84 for the degraded area, that is, the low value reflects that there is less uniformity regarding the plant distribution in the degraded area. According to the diversity indices, we can see that the degraded area loses its diversity in species, that is, it loses its richness that can influence the characteristics of the soil, fauna and biotic and abiotic interactions.
\end{abstract}

Keywords: Caatinga; Species; Indexes; Preservation. 


\begin{abstract}
Resumen
El objetivo de este trabajo fue recolectar e identificar especies nativas de la composición floristería en dos áreas diferenciadas de la ciudad de Salgueiro-PE. La recolección se realizó en el municipio de Formiga, en un área de bosque nativo preservado y en el sitio de Uri, donde se observó el área degradada. En todas las áreas se demarcaron 2 transectos rectangulares $(10 \times 30 \mathrm{~m})$ y se distribuyeron alrededor de cada área, cada transecto estuvo compuesto por tres parcelas cuadrangulares $(10 \times 20 \mathrm{~m})$ separadas por un intervalo de $10 \mathrm{~m}$. Se recolectaron 102 especies en el área degradada y se distribuyeron en familias botánicas. En el área preservada se encontraron 375 individuos pertenecientes a diferentes familias y especies, teniendo un mayor número de especies, es decir, mayor biodiversidad y una rica variedad de árboles y arbustos en relación al área degradada. El valor de Shannon-Weaver (H ') encontrado en el área degradada (A) 1.75 y en el área preservada (B) 2.51, indica que el área B es más diversa y que A. ¿Qué pasa con el índice de dominancia de Simpson (C) el valor observado? fue 0,90 en el área (A) y 0,76 en el área (B). Los valores de uniformidad observados fueron 0.90 para el área preservada y 0.84 para el área degradada, es decir, el valor bajo refleja que hay menos uniformidad en la distribución de plantas en el área degradada. De acuerdo con los índices de diversidad, podemos ver que el área degradada pierde su diversidad en especies, es decir, pierde su riqueza que puede influir en las características del suelo, la fauna y las interacciones bióticas y abióticas.
\end{abstract}

Palabras clave: Caatinga; Especies; Índices; Preservación.

\title{
1. Introdução
}

Caatinga é um termo originado do Tupi, que significa "mata branca", lembrando o aspecto da sua vegetação no período de estiagem, isto é, na estação seca, período este em que a grande maioria das árvores se desfolha e os seus troncos dominam as paisagens (Prado, 2003).

Dentre os biomas brasileiros, a Caatinga é, provavelmente, o mais desvalorizado e mal conhecido botanicamente. Esta situação decorre de uma crença injustificada, e que não deve ser mais aceita, pois já se sabe que a caatinga possui uma diversidade de espécies de plantas e animais e algumas delas endêmicas Giulietti et al, (2006).

A vegetação da caatinga apresenta grande número de espécies botânicas, entre elas herbáceas, arbustivas e arbórea. Segundo Drumond et.al., (2000) a flora originária da Caatinga apresenta espécies vegetais com caracteres anatômicos, morfológicos e funcionais exclusivos para a sobrevivência destas plantas às condições adversas de clima e solo, característicos desta fisionomia. Quanto à biodiversidade vegetal da Caatinga, esta tem uma diversidade florística elevada, mesmo se tratando de um bioma com uma forte limitação ao crescimento como a deficiência hídrica. Em geral, áreas de Caatingas típicas possuem menos de 50 espécies arbustivas e arbóreas com igual quantidade de herbáceas por hectare (Giulietti et.al. 2006). Oliveira et al., (2020) enfatiza que no Brasil a caatinga é a vegetação característica de uma zona de clima atípico para a região em que se encontra e que historicamente sofreu com a exploração desordenada, causada por sucessivos ciclos econômicos com o desmatamento e consequente perda de biodiversidade. A agricultura, uma das atividades responsáveis pela degradação história das Caatingas, além de outras atividades, considerada limpa, renovável e de baixo potencial poluidor, como é o caso das eólicas, também vem demandando grandes áreas de supressão de vegetação nativa para a sua implantação no Estado (Oliveira, 2016).

No seu estudo Miles et al, (2006) mostra que a Caatinga é um dos ecossistemas mais ameaçados do mundo, com altos índices de espécies ameaçadas de extinção, em razão das inúmeras ameaças antrópicas, como o desmatamento para implantação da agricultura e pasto, e as alterações em função das mudanças climáticas.

No entanto, a preocupação com os recursos da Caatinga possui registros históricos, manifestada por autores de significativa importância, tanto na literatura quanto na pesquisa acadêmica, destacando-se Euclides da Cunha que, em "Os Sertões”, apresentava o valor da biodiversidade da caatinga e a diversidade das paisagens do Semiárido nordestino, ao mesmo tempo em que denunciava a destruição pela sua grande ameaça: o homem e a sua ferramenta inseparável de conquista, o fogo (Gariglio, 2010). O uso sustentável e a conservação dos recursos florestais do bioma Caatinga Na Região Nordeste do Brasil percorrem duas questões fundamentais. A primeira está relacionada à sua importância para a manutenção da economia regional, e a segunda caracteriza-se pela comercialização de produtos florestais madeireiros e não-madeireiros, além de servir como forragem para os animais criados de forma extensiva no bioma Gariglio et al, (2020). 
É notório que a fauna auxilia na manutenção da umidade do solo, como também na diminuição das temperaturas elevadas e da extensão térmica (Torres et.al. 2006). Além disso, protegem os solos contra os principais agentes causadores de degradação. As espécies herbáceas durante estações adversas apresentam inúmeras adaptações como estratégia de sobrevivência às condições impostas pelo ambiente semiárido (REIS et.al., 2006), permitindo a eficiência da regeneração do grupo, por meio de sementes, bulbos e rizomas, em época de chuvas. Segundo Guedes et al, (2012) estudos sobre a composição florística e a estrutura dos remanescentes de caatinga são importantes, constituindo ferramenta para o entendimento de aspectos da ecologia regional, fornecendo bases para a sua conservação ou exploração sustentável. A degradação do bioma Caatinga ameaça toda a biodiversidade existente na região, além disso afeta o desenvolvimento e a manutenção de atividades ligadas ao social, econômico e cultural. Isso gera impactos em outras áreas relacionadas direta ou indiretamente à boa manutenção desse bioma (Brasileiro, 2009). Oliveira, 2016 destaca as variações climáticas e seus prováveis impactos ambientais, consequências do uso dos recursos naturais, evidenciando a necessidade de controle do desmatamento no bioma Caatinga por parte do Estado, a fim de evitar a degradação desse bioma e concretização dos desastrosos impactos previstos.

De acordo com Santana et al., 2021 cada vez mais se faz necessário estudos que utilizem a identificação e a conservação das espécies da Caatinga e o conhecimento sobre a flora possibilita uma base para a tomada de decisões em relação aos métodos e técnicas adequadas em ações futuras de manejo. Dessa forma o objetivo desse trabalho foi coletar e identificar espécies nativas da composição florista em três áreas diferentes na cidade de Salgueiro PE para que os dados coletados fossem analisados e comparados.

\section{Metodologia}

O presente trabalho originou- se durante uma aula prática da disciplina de Ecologia do curso de licenciatura em Ciências Biológicas na Faculdade de Ciências Humanas do Sertão Central- FACHUSC. Realizado no município de Salgueiro, localizado no interior do Estado de Pernambuco, a cerca de $445 \mathrm{~km}$ da capital (Coordenadas 0804'27" S/ 3907'09" W), está situado na mesorregião do Sertão de Pernambuco na microrregião de Salgueiro, limitando-se ao Norte com Penaforte (CE) ao Sul com Belém de São Francisco e a Oeste com Terra Nova, o local está com 420 metros de elevação (Paulo \& Quirino, 2014). Segundo IBGE, (2020) Possui uma área Territorial de 1.678,564 km², uma População estimada de 61.249 pessoas e uma Densidade demográfica 33,57 hab $/ \mathrm{km}^{2}$. Típico do clima semi árido suas temperaturas anuais de $26^{\circ} \mathrm{C}$, clima tropical chuvoso e vegetação de Caatinga xeromórfica. Segundo SECTMA, 2004 o município estudado fica localizado em uma das mais populosas regiões semiáridas do mundo, entretanto, é a região menos conhecida do ponto de vista dos seus recursos naturais, principalmente sobre biodiversidade, além de ser a menos atendida e protegida (SECTMA, 2004). Utilizou-se de uma pesquisa descritiva e do método quantitativo que segundo Zanella (2011) esse método preocupa-se com representatividade numérica, ou seja, com a medição objetiva e a quantificação dos resultados. Tem como objetivo generalizar os dados a respeito de uma população, estudando somente uma pequena parcela dela. A principal razão para a escolha desse método de pesquisa foi comparar o número de indivíduos e de espécies encontradas nas áreas estudadas.

A coleta de dados foi realizada em duas áreas distintas na cidade de Salgueiro PE. Sendo a primeira área escolhida no município de Salgueiro Formiga, em uma área de mata nativa preservada. A segunda visita foi no sítio Uri, onde foi visto a área degradada, nessa área podemos perceber a ação antrópica desencadeando uma série de fatores negativos na vegetação da caatinga. O solo era compactado, ou seja, tinha pouca porosidade comprometendo o desenvolvimento das raízes das plantas, exposto a luz do sol devido possuir pouca matéria orgânica. Foi realizado através do método de amostragem e em todas as áreas foram demarcados 2 transectos retangulares $(10 \times 30 \mathrm{~m})$ distribuídos no entorno de cada área, cada transecto era composto por três parcelas quadrangulares $(10 \times 20 \mathrm{~m})$ separadas por um intervalo de $10 \mathrm{~m}$. Foram considerados apenas os indivíduos, arbustivos e arbóreos que se encontravam com o colo no interior da parcela. Após levantamento das espécies em campo, foi 
realizado a identificação das espécies com os nomes vernáculos, sua contagem (número de indivíduos, espécies e famílias), seu detalhamento botânico e para a identificação à nível de família, foram utilizadas chaves de identificação de Souza e Lorenzi (2012) onde foi levado em consideração as características morfológicas e anatômicas. Para análise dos dados foi utilizado o software Past, onde foi calculado os índices de Shannon, Simpson e a equabilidade de Pielou (J').

\section{Resultados e Discussão}

Foram coletadas 102 espécies na área degradada e distribuídas em famílias botânicas. Essas espécies foram determinadas em nível de família, espécies e nome vernáculo, como mostra na Tabela 1. Na área degradada podemos perceber o solo compactado, ou seja, tinha pouca porosidade comprometendo o desenvolvimento das raízes das plantas, exposto a luz do sol devido possuir pouca matéria orgânica devido a ação antrópica que segundo Vieira (2021) são ações que geram maiores e profundas transformações, no momento atual é caracterizada pelos impactos ambientais negativos, e suas consequências para o futuro tais ações podem ser entendidas como qualquer interação com o meio natural. Em relação às espécies encontradas na área degradada verificou-se uma perda da biodiversidade. Na parcela 1 foram encontradas 7 espécies diferentes de arbustos e arbóreos. As espécies encontradas foram respectivamente Marmeleiro (Croton sonderianus), Faveleira (Cnidoscolus quercifolius Pohl), Jurema branca (Piptadenia stipulacea), pião (Jatropha curcas), anil de bode (Tephrosia cinerea (L.)), e pereiro (Aspydosperma pyrifoluim Mart), estas mesmas espécies foram encontradas nas parcelas 2 e 3 . As famílias que apresentaram maior número no presente estudo foram respectivamente Euphorbiacea (77 espécies), Fabaceae (18 espécies) e família Apocynaceae (2 espécies) conforme visto na Tabela 1. Corroborando com Silva e Ramos, (2019) a família Euphorbiaceae foi a predominante na área, possivelmente pelo fato de as espécies desenvolver características morfosiológicas que as mantenham resistentes as formas do ambiente em que se encontram. Assemelhando-se com outras áreas de Caatinga, observou-se que as famílias botânicas mais importantes quanto ao número de espécies são Fabaceae, Euphorbiaceae e Anacardicaceae (Ferraz et al.,2013). 
Tabela 1. Lista de espécies arbustivas e arbóreas encontradas na área degradada no sítio Uri.

\begin{tabular}{|c|c|c|}
\hline Família Botânica & $\begin{array}{c}\text { Nome } \\
\text { Científico }\end{array}$ & Nome Vernáculo \\
\hline Apocynaceae & $\begin{array}{c}\text { Aspydosperma } \\
\text { pyrifoluim } \\
\text { Mart. }\end{array}$ & Pereiro \\
\hline \multirow{4}{*}{ Euphorbiaceae } & $\begin{array}{c}\text { Croton } \\
\text { sonderianus }\end{array}$ & Marmeleiro \\
\hline & $\begin{array}{l}\text { Müll.Arg. } \\
\text { Jatropha } \\
\text { curcas L. }\end{array}$ & Pião Branco \\
\hline & $\begin{array}{c}\text { Jatropha } \\
\text { gossypiifolia } \\
\text { L. }\end{array}$ & Pião Roxo \\
\hline & $\begin{array}{c}\text { Cnidoscolus } \\
\text { quercifolius } \\
\text { Pohl. }\end{array}$ & Sambao \\
\hline Fabaceae & $\begin{array}{c}\text { Indigofera } \\
\text { tinctoria } \mathrm{L} . \\
\text { Croton } \\
\text { conduplicatus } \\
\text { Kunth. } \\
\end{array}$ & $\begin{array}{c}\text { Anil } \\
\text { Jurema Branca }\end{array}$ \\
\hline Verbenaceae & $\begin{array}{c}\text { Lippia } \\
\text { sidoides } \\
\text { (Cham.) }\end{array}$ & Alecrim \\
\hline
\end{tabular}

Fonte: Autores (2021).

A área preservada encontrava -se no município de Salgueiro Formiga, onde foi observado o solo, o clima, a umidade relativa do ar, a fauna e a flora. Com base nas observações podemos comparar a área degradada com a área preservada, visto que o solo na área preservada era visivelmente mais produtivo, pois possuía mais matéria orgânica, consequentemente mais microrganismos além ser um ambiente mais úmido. A quantidade de espécies também foi bem maior comparada a área degradada o que podemos chamar de "mata fechada". Nessa área foram encontrados 375 indivíduos pertencentes a famílias e espécies diferentes, possuindo um número maior de espécies, ou seja, uma maior biodiversidade. Corroborando com silva et al, (2021) uma rica variedade arbóreo-arbustiva em relação a área degradada (B) além de possuírem relevante diversidade de indivíduos, apresentaram pequenas concentrações de representantes semelhantes nas famílias, considerando a identidade florística de cada grupo caracterizada pela presença de seres da mesma espécie pouco abundantes, mas com alto percentual em espécies distintas. 
Tabela 2. Lista de espécies arbustivas e arbóreas encontradas na área preservada no munícipio formiga na cidade de Salgueiro.

\begin{tabular}{|c|c|c|}
\hline Família Botânica & $\begin{array}{c}\text { Nome } \\
\text { Científico }\end{array}$ & Nome Vernáculo \\
\hline Apocynaceae & $\begin{array}{c}\text { Aspydosperma } \\
\text { pyrifoluim } \\
\text { Mart. }\end{array}$ & Pereiro \\
\hline Asteraceae & $\begin{array}{l}\text { Mikania } \\
\text { glomerata } \\
\text { Sprengel. }\end{array}$ & Quebra Faca \\
\hline Boraginaceae & $\begin{array}{c}\text { Cordia } \\
\text { leucocephala } \\
\text { Moric. }\end{array}$ & Moleque Duro \\
\hline Burseraceae & $\begin{array}{c}\text { Commiphora } \\
\text { leptophloeos } \\
\text { (Mart.) } \\
\text { Gillett). } \\
\end{array}$ & Emburana de Cheiro \\
\hline Cactaceae & $\begin{array}{c}\text { Pilocereus } \\
\text { gounellei } \\
\text { F.A.C.Weber } \\
\text { ex K.Schum. }\end{array}$ & Xique Xique \\
\hline Capparaceae & $\begin{array}{c}\text { Cynophalla } \\
\text { flexuosa (L.) } \\
\text { J.Presl. }\end{array}$ & Feijão Bravo \\
\hline Euphorbiaceae & $\begin{array}{c}\text { Croton } \\
\text { sonderianus } \\
\text { Müll.Arg. } \\
\text { Jatropha } \\
\text { curcas L. }\end{array}$ & $\begin{array}{l}\text { Marmeleiro } \\
\text { Pião Branco }\end{array}$ \\
\hline \multirow[t]{4}{*}{ Fabaceae } & $\begin{array}{c}\text { Tephrosia } \\
\text { cinerea (L.) } \\
\text { Pers. }\end{array}$ & Anil \\
\hline & $\begin{array}{c}\text { Croton } \\
\text { conduplicatus } \\
\text { Kunth }\end{array}$ & Jurema Branca \\
\hline & $\begin{array}{c}\text { Mimosa } \\
\text { tenuiflora } \\
\text { (Mart.) Benth. }\end{array}$ & Jurema Preta \\
\hline & $\begin{array}{c}\text { Bauhinia } \\
\text { cheilantha } \\
\text { (Bong.) Steud. }\end{array}$ & Mororó \\
\hline Família Botânica & $\begin{array}{c}\text { Nome } \\
\text { Científico } \\
\end{array}$ & Nome Vernáculo \\
\hline Leguminosae & $\begin{array}{l}\text { Caesalpinia } \\
\text { pyramidalis } \\
\text { Tul. } \\
\text { Anadenanthera } \\
\text { macrocarpa } \\
\text { Benth. }\end{array}$ & Angico Manso \\
\hline Rubiaceae & $\begin{array}{c}\text { Uncaria } \\
\text { tomentosa } \\
\text { (Willd. DC.) } \\
\end{array}$ & Unha de Gato \\
\hline
\end{tabular}


A diversidade florística e a abundância relativa das espécies analisadas por meio do índice de diversidade de ShannonWeaver (H') calculados no Past onde foi encontrado na área degradada (A) 1, 75 e na área preservada (B) 2,51. O índice de Shannon (base neperiana) indica que área B é mais diversa e que A. A área estudada (A) apresentou uma maior diversidade arbóreo-arbustiva encontrada nas coletas, que além de possuírem relevante diversidade de indivíduos, apresentaram pequenas concentrações de representantes semelhantes nas famílias, considerando a identidade florística de cada grupo caracterizada pela presença de seres da mesma espécie pouco abundantes (Silva et al, 2021). E quanto ao índice de dominância de Simpson (C) que ocorre na escala que varia de 0 a 1, o valor observado neste estudo foi de 0,90 na área (A) e 0,76 na área (B), com esses valores podemos entender que na área preservada (A) há uma maior abundancia de espécies e consequentemente uma maior diversidade. O índice de diversidade de Shannon baseia-se na teoria da informação e fornece uma ideia do grau de incerteza em prever, a qual espécie pertenceria um indivíduo retirado aleatoriamente da população. No entanto, um o valor de diversidade de Shannon-Wiener (H’) foi baixo se comparados com Costa Júnior et al. Já o índice de Simpson, tem formulação derivada da teoria das fornecendo a ideia da probabilidade de se retirar aleatoriamente dois indivíduos da comunidade que pertencerem às espécies diferentes (Gorenstein, 2002). A seguir, apresenta-se os gráficos com os índices calculados no Past.

Gráfico 1. Índice de Shannon (H').

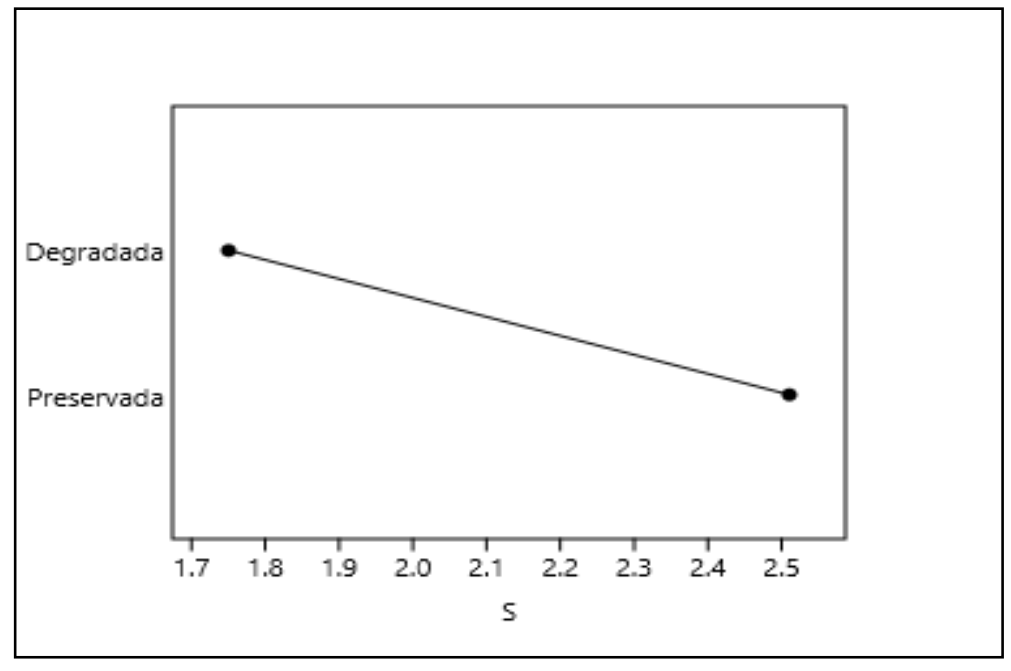

Fonte: Autores.

Gráfico 2. Índice de Simpson.

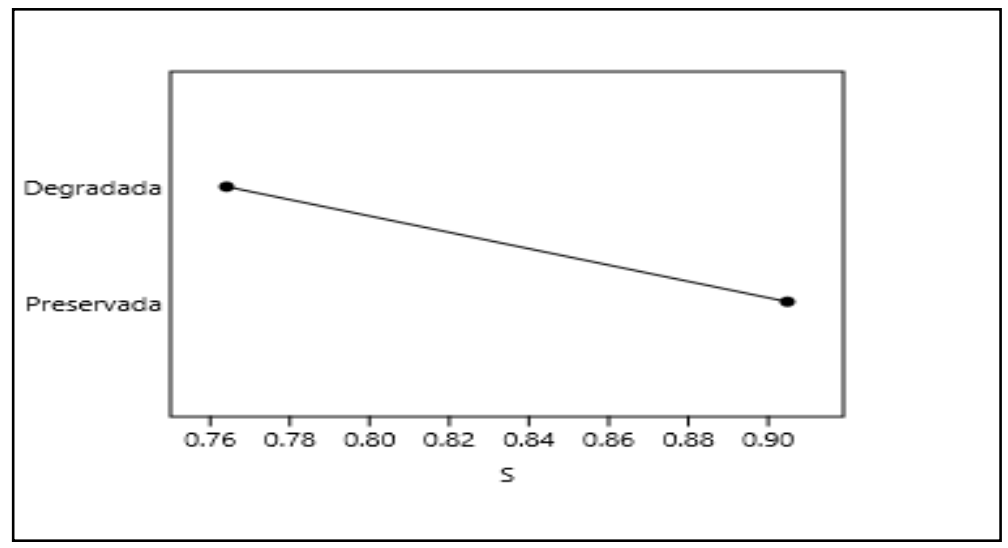

Fonte: Autores. 
Quando observados o índice de equabilidade de Pielou (J') derivado do índice de diversidade de ShannonWeaver, no qual permite representar a uniformidade da distribuição dos indivíduos entre as espécies existentes na área, os seus valores também variam de 0 a 1, em que quanto mais próximo de 1 mais abundante é a área. Batista et al, (2019). O valor observado neste estudo foi de foi de 0,90 para a área preservada e 0,84 para a área degradada, ou seja, que o baixo valor da equabilidade constatado reflete que há uma menor uniformidade referente à distribuição vegetal na área degradada. Com isso, pode-se constatar que a degradação da caatinga implica em baixa riqueza e diversidade, porem grande heterogeneidade ambiental e baixa dominância ecológica. No gráfico abaixo pode ser observado de forma clara a variação desse índice em cada área vista.

Gráfico 3. Índice de equitabilidade.

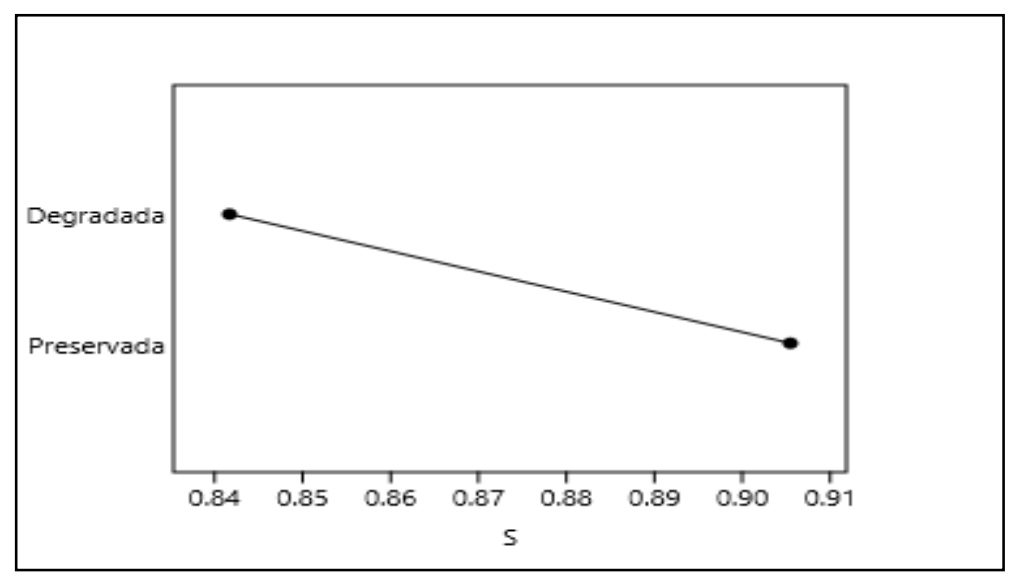

Fonte: Autores.

\section{Conclusão}

Mediante os resultados obtidos no decorrer deste estudo, foi possível observar e comparar as duas áreas vistas. Podemos perceber que as famílias Fabaceae e Euphorbiaceae são as que apresentaram o maior número de espécies arbustivo arbóreas nas duas áreas de estudo o que confirma o padrão para o semiárido brasileiro, pois estas famílias possuem mecanismos de sobrevivência contra a falta de água e a baixa umidade relativa do ar. No entanto, foi verificado um número maior de indivíduos na área preservada já que esta não sofreu ação antrópica, além de um número maior para outras famílias botânicas e espécies endêmicas o que demostra uma preocupação com as áreas degradadas de caatinga, pois nota-se uma perda de biodiversidade devido ao uso dos recursos naturais. De cordo com os índices de diversidade podemos perceber que a área degradada perde sua diversidade em espécies, ou seja, perde sua riqueza que pode influenciar nas características do solo, da fauna e nas interações bióticas e abióticas. Diante disso, torna-se evidente a importância de estudos florísticas na Caatinga através levantamentos e inventários, além de pesquisas em campo que favoreçam a conservação da fauna e flora. Estudos que levem a uma maior conscientização, uma diminuição da degradação e um uso sustentável dos recursos naturais existentes nesse Bioma brasileiro.

\section{Referências}

Batista, F. G., Oliveira, B. T. de., Almeida, M. E. A. de., Brito, M. S. de., Melo, R. R. de \& Alves, A. R. (2019). Florística e fitossociologia de um remanescente florestal da caatinga Caicó- RN, Brasil. Revista Desafios. 6(3).

Brasileiro, R. S. (2009). Alternativas de desenvolvimento sustentável no semiárido nordestino: da degradação à conservação. Scientia Plena, São Cristóvão, Sergipe, 5(5), 1-12.

Costa Júnior, R. F., Ferreira, R. L. C., Rodal, M. J. N., Feliciano, A. L. P., Marangon, L. C.; Silva \& Wegliane C. (2007). Florística arbórea de um fragmento de Floresta Atlântica em Catende, Pernambuco - Nordeste do Brasil. Revista Brasileira de Ciências Agrárias, 2(4), $297-302$. 
Drumond. M. A., Kiill L. H. P., Lima. P. C. F., Oliveira M. C., Oliveira V. R., Oliveira, E. R. de., Albuquerque, S. G. de Nascimento, C. E. de S \& Cavalcanti, J. (2000). Estratégias para o Uso Sustentável da Biodiversidade da Caatinga. Documento para discussão no GT Estratégias para o Uso Sustentável, Petrolina.

Ferraz, C, R., Anabel, A. M. de., Ferreira. R. A., Prata. N. A. P. do. (2013). Levantamento fitossociológico em área de caatinga no monumento natural grota do angico, sergipe, brasil Revista Caatinga, 26(3), 89-98

Gariglio, M. A., Sampaio, E. V. S. B. de., Cestaro, L. A \& Kageyama, P. Y. (2010). Uso sustentável e conservação dos recursos florestais da caatinga. Brasília: Serviço Florestal Brasileiro, 2010. 368p. organizadores. Brasília: Serviço Florestal Brasileiro, 368p.: il. color.; 23 cm.

Giullieti, A. M., Conceicao, A \& Queiroz, L. P. (2006). Diversidade e caracterização das fanerógamas do semiárido brasileiro. Recife: Associação Plantas do Nordeste, 488 p.7.

Gorenstein, M. R. (2002). Métodos de amostragem no levantamento da comunidade arbórea em Floresta Estacional Semidecidual. 92 f. Dissertação (Mestrado em Recursos Florestais) - Escola Superior de Agricultura "Luiz de Queiroz", Universidade de São Paulo.

Guedes, R. S., Zanella, F. C. V. Júnior., Costa, J. E. V., Santana, G. M \& Silva, J. A. (2012). Caracterização florístico-fitossociológica do componente lenhoso de um trecho de caatinga no semiárido paraibano. Revista Caatinga, 25(2), 99-108.

Lorenzi, H. (2000). Plantas daninhas do Brasil: terrestres, aquáticas, parasitas, tóxicas e medicinais. (3a ed.), Instituto Plantarum.

Moreira, H. J. C. da. \& Bragança. (2011). Horlandezan Belirdes Nippes. Manual de identificação de plantas infestantes: Hortifrúti. FMC Agricultural .1017 p.

Oliveira, Í. P. de., Cruz, M. L. B. da \& Sousa, L. F. de (2020). Riqueza e diversidade da caatinga em área de transição entre sertões semiáridos e brejos de altitude no Ceará, Revista GeoNordeste, 1, 27-43.

Oliveira, P. D. M. (2016). Desmatamento nas caatingas pernambucanas: uma análise da supressão de vegetação autorizada pelo Estado, Dissertação apresentada ao Programa de Pós-Graduação em Desenvolvimento e Meio Ambiente da UFPE, Recife.

Paulo, F. L. L. de \& Quirino, A. M. S. (2014). Gestão urbana e arborização das cidades: diagnóstico qualitativo e quantitativo no município de salgueiro, Pernambuco, Brasil. X Fórum Ambiental da Alta Paulista, 10(4), 46-57

Prado, D. (2003). As caatingas da América do Sul. In: Leal, I. R.; Tabarelli, M.; Silva, J. M. C.(Ed.). Ecologia e conservação da Caatinga. Recife: Editora Universitária, UFPE. p. 3-73.

Reis, A. M. S., Araújo, E. L.; Ferraz, E. M. N., et al. (2006). Inter-annual in the floristic and population structure of an herbaceous community of "caatinga" vegetation in Pernambuco, Brazil. Acta Botânica Brasilica. 29, 497-508.

SECTMA-conselho nacional da reserva da biosfera da caatinga. (2004). Cenários para o Bioma Caatinga. Secretaria de Ciência, Tecnologia e Meio Ambiente. Recife, 283p.

Silva, L. E. B., Souza, G. S. de., Lima, L. L. C \& Lopes, E. A. P., (2021). Levantamento florístico de famílias botânicas em estrato arbóreo arbustivo no município de Arapiraca- AL, Diversitas Journal. 6(1), 276-290.

Torres, J. L. R., Fabian, A. J., Pereira, M. G., \& Andrioli, I. (2006). Influência de plantas de cobertura na temperatura e umidade do solo na rotação de culturas milho-soja em plantio direto. Revista Brasileira de Agrociência, 12(1), 107-113.

Vieira, J. V. B. (2021). Agroecologia: métodos e técnicas para uma agricultura sustentável. - V. 1: Agroecologia e ações antrópicas de bases mais sustentáveis Bahia: Editora Científica Digital.

Zanella, L. C. H. (2011). Metodologia de pesquisa. (2a ed.), Departamento de Ciências da Administração/UFSC,.134 p.: il 